\title{
Izboljšave modela za kratkoročno napoved pojava žledoloma v Sloveniji
}

\section{Nikica OGRIS $^{1^{*}}$ in Neva PRISTOV ${ }^{2}$}

V letu 2016 smo razvili model za napoved debeline žleda in nevarnosti žledoloma do 12 ur v naprej (Ogris in sod., 2016) s prostorsko ločljivost $1 \mathrm{~km}$ in časovno ločljivostjo 1 ure. Vir meteoroloških podatkov za oceno debeline žleda je sistem za kratkoročno napoved INCA (ARSO), iz katerega model črpa podatke o količini dežja, ki zmrzuje, hitrosti vetra in temperaturi zraka. Model za oceno debeline žleda simulira tudi taljenje žleda. Model za oceno nevarnosti žledoloma je empirični model na osnovi indeksa, v katerega smo vključili debelino žleda, indeks drevesne sestave, naklon terena in indeks matične podlage.

Model za napoved debeline žleda in nevarnosti žledoloma smo nadgradili z možnostjo napovedi do 72 ur v naprej. Vhodne meteorološke podatke dobimo iz numeričnega meteorološkega modela ALADIN-SI (Pristov in sod., 2002), s prostorsko ločljivost 4,4 km, meteorološke spremenljivke pa napove za 72 ur v naprej na vsako uro. $\mathrm{Na}$ ARSO so dodali izračun dodatne spremenljivke, tj. tip padavin, ki je ena ključnih spremenljivk v modelu za oceno debeline žleda. Znotraj ALADIN modela so padavine razdeljene $v$ dežne in snežne, dodana pa je še diagnostika za pojav dežja, ki zmrzuje. Postopek izračuna debeline žleda in nevarnosti žledoloma je identičen kot pri podatkih iz sistema INCA z dvema izjemama: vir podatkov za prejšnjo debelino žleda in spremenljivko, ki jo model uporablja za taljenje ledu (število ur, ko je temperatura zraka večja kot $0^{\circ} \mathrm{C}$ ) je sistem INCA. Slednji spremenljivki temeljita na analizi podatkov avtomatskih meteoroloških postaj, zato so podatki točnejši kot prognostični podatki modela ALADIN-SI. Polji le interpoliramo na redkejšo mrežo. Vir podatkov o količini dežja, ki zmrzuje, hitrosti vetra in temperaturi zraka za tri dnevno napoved pa je model ALADIN-SI.

Postopek se prične z odjemom napovedi izbranih količin iz ALADIN-SI: padavine (P), tip padavin (PT), hitrost vetra ( $\mathrm{U}$ in $\mathrm{V}$ komponenta), temperatura zraka (slika 1). Podatke prevzamemo na FTP strežniku ARSO. Vse prenesene podatke shranimo $\mathrm{v}$ prostorsko podatkovno zbirko (GeoDB, Microsoft SQL Server). Sledi izračun $T_{0}$ (število ur, ko je temperatura zraka večja kot 0 ${ }^{\circ} \mathrm{C}$ ) in V (hitrost vetra) in sicer za naslednjih 72 ur. Prejšnjo vrednost $T_{0}$ prevzamemo iz podatkov sistema
INCA, prihodnje $T_{0}$ pa temeljijo na podatkih temperature modela ALADIN. Vrednosti $T_{0}$ shranimo v podatkovno zbirko (GeoDB). Potem na podlagi $R_{j-1}$ (prejšnja debelina žleda, INCA), $P$ (količina padavin, ALADIN), $P T$ (tip padavin, ALADIN), $T_{0}$ in V (hitrost vetra, ALADIN) izračunamo debelino žledu $R_{e q}$, za naslednjih 72 ur, ki jo prav tako shranimo v podatkovno zbirko GeoDB. Sledi izračun ranga debeline žledu na podlagi $R_{e q}$ in izračun napovedi nevarnosti pojava žledoloma (S) iz spremenljivk DV (indeks drevesne sestave), Naklon (naklon terena), Kamnina (indeks matične podlage) in ranga $R_{e q}$ za obdobje 72 ur. Izračunane vrednosti (S) shranimo $\mathrm{v}$ podatkovno zbirko (GeoDB). Proces se konča z izdelavo slik in animacij debeline žledu $\left(R_{e q}\right)$ in ocene nevarnosti pojava žledoloma $(S)$, ki jih shranimo v podatkovno zbirko EVG (Ogris, 2012). Podatki za prikazovanje rezultatov modela na spletnem portalu za varstvo gozdov (www.zdravgozd.si) se črpajo iz podatkovne zbirke GeoDB in EVG.

Dopolnili smo spletno aplikacijo za prikaz kratkoročne napovedi debeline žleda in pojava žledoloma $\mathrm{v}$ Sloveniji

(http://www.zdravgozd.si/prognoze zapis.aspx?idpor=30), kjer je poleg 12 urne napovedi na voljo še napoved za 72 ur v naprej. Napoved si lahko ogledamo s pomočjo animacije ali spletne interaktivne karte (slika 2 in 3 ).

\section{Viri}

Ogris N., Pristov N., Kobler A. 2016. Model za kratkoročno napoved pojava žledoloma v Sloveniji. Napovedi o zdravju gozdov, 2016. http://www.zdravgozd.si/prognoze zapis.aspx?idpor=29. DOI: $10.20315 / \mathrm{NZG} .29$

Ogris N. 2012. Prognostične osnove za varstvo gozdov Slovenije. Ljubljana, Silva Slovenica: 104 str.

Pristov N., Cedilnik J., Jerman J., B. S. 2012. Priprava numerične meteorološke napovedi ALADIN-SI. Vetrnica, 4: 17-22.

${ }^{1}$ Gozdarski inštitut Slovenije, Večna pot 2, 1000 Ljubljana; ${ }^{2}$ Agencija Republike Slovenije za okolje, Vojkova 1b, 1000 Ljubljana *nikica.ogris@gozdis.si 


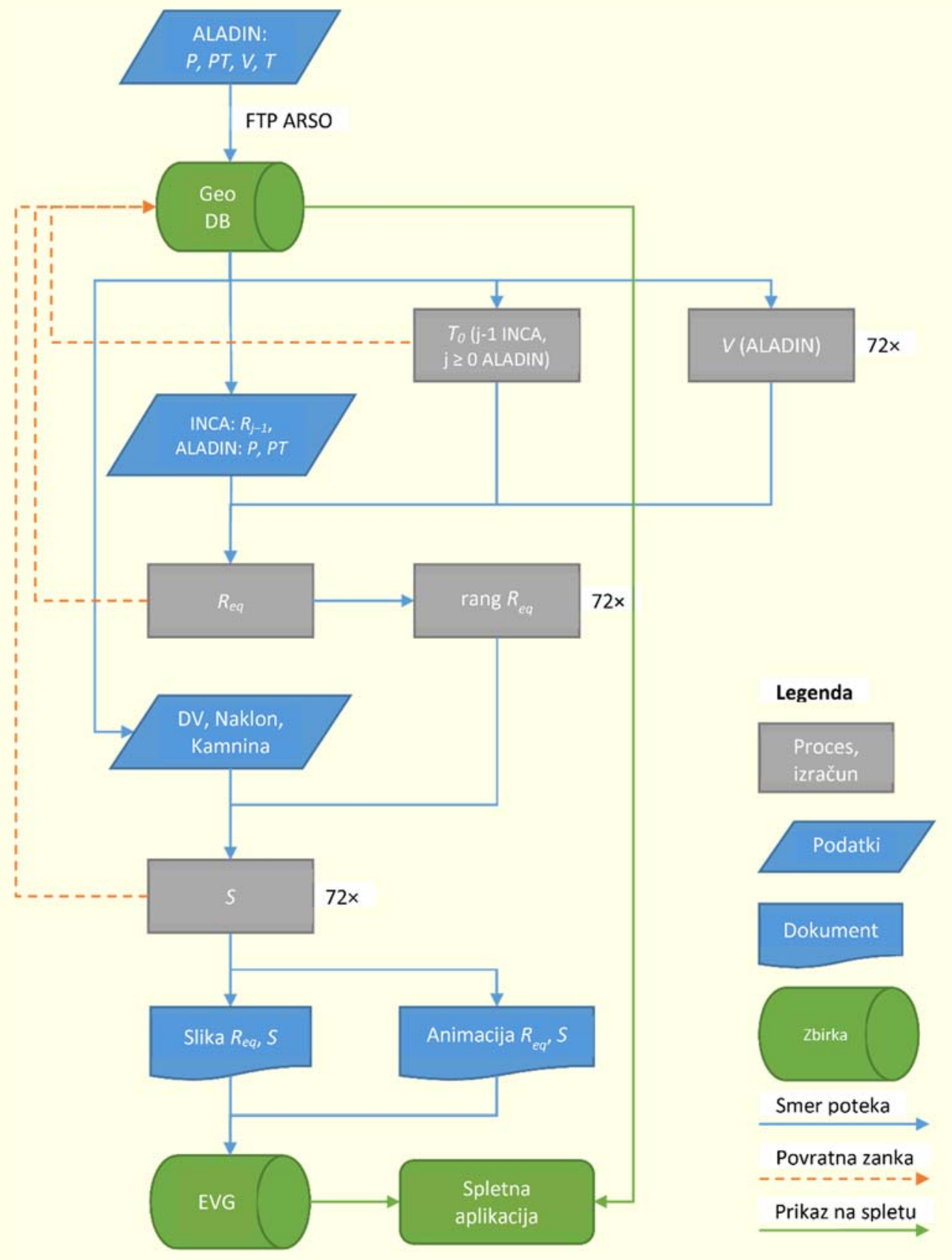

Slika 1: Shema modela za napoved pojava žledoloma za 72 ur v naprej

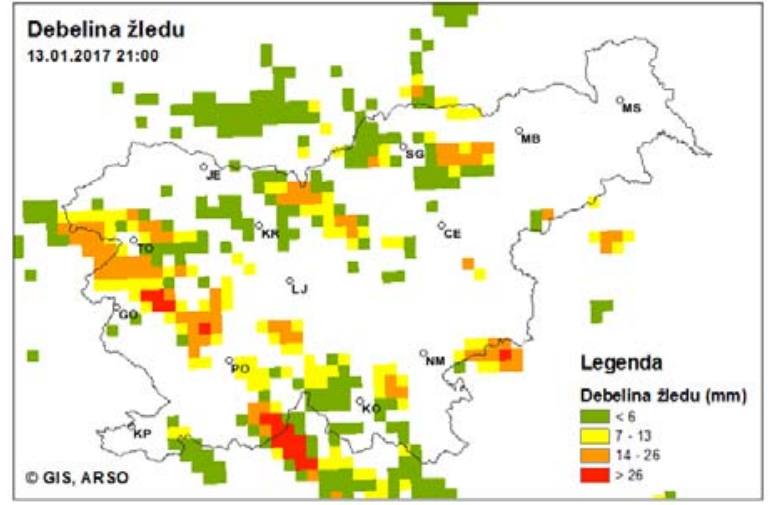

Slika 2: Primer napovedi za debelino žleda 13. 1. 2017 ob 21:00

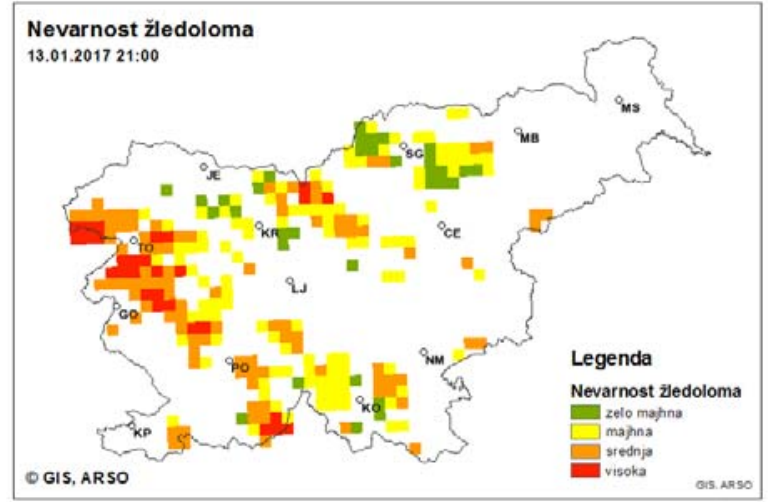

Slika 3: Primer napovedi za nevarnost žledoloma 13. 1. 2017 ob 21:00 